Article

\title{
Evaluating Impacts of a One Health Approach to Companion Animal Health and Management in a Remote Aboriginal Community in the Northern Territory, Australia
}

\author{
Tamara Riley ${ }^{1, *(\mathbb{D})}$, Raymond Lovett ${ }^{1}$ (D) Joanne Thandrayen ${ }^{1}$, Bonny Cumming ${ }^{2}$ \\ and Katherine A. Thurber ${ }^{1}$ \\ 1 National Centre for Epidemiology and Population Health, Research School of Population Health, \\ The Australian National University, Canberra, ACT 2600, Australia; raymond.lovett@anu.edu.au (R.L.); \\ joanne.thandrayen@anu.edu.au (J.T.); katherine.thurber@anu.edu.au (K.A.T.) \\ 2 Animal Management in Rural and Remote Indigenous Communities, Darwin, NT 0801, Australia; \\ bonny.cumming@amrric.org \\ * Correspondence: tamara.riley@anu.edu.au
}

Received: 28 July 2020; Accepted: 23 September 2020; Published: 1 October 2020

Simple Summary: Many remote Australian Aboriginal communities face barriers in accessing animal health care for their pets. A community that faces these barriers implemented a community-driven program with the objective of improving animal health and population management. The program was evaluated by comparing the percentage of animals desexed, the body and hair condition of dogs, and the presentations at the health clinic for dog bites before versus after 12 months of program implementation. Results show improved animal health measures and no measurable change in human presentations for dog bites. This program, with One Health considerations, could be suitable for other communities facing similar animal health care barriers.

\begin{abstract}
This study evaluated a community-driven animal health and management program in the remote community of Wadeye, Northern Territory. This evaluation used a pre-post design to assess changes in animal and human health outcomes over a 12-month period of program implementation, from June 2018 to June 2019. The evaluation assessed the program by comparing animal health outcomes before versus one year after program implementation and comparing human health outcomes before versus during the first 12 months of the program. Outcome measures included the desexing status of dogs and cats, body condition and hair score of dogs, and rates of people presenting to the health clinic for a dog bite. Animal health outcomes significantly improved after program implementation. From pre to post program, there was a $77 \%$ increase in the prevalence of good body condition score among dogs and a $9 \%$ increase in the prevalence of good hair score among dogs, and the prevalence of desexed dogs and cats more than doubled. There was no significant change in the number of people presenting to the health clinic for a dog bite. Consideration on how to further incorporate human and environmental health aspects into the program could be useful for future One Health programs.
\end{abstract}

Keywords: Aboriginal community; animal health; remote; One Health; dogs; cats; population management

\section{Introduction}

The World Health Organization estimates that $61 \%$ of all human pathogens are zoonotic (can be transmitted between animals and people) and 75\% of emerging diseases affecting people in the last 
decade have originated from animals [1]. The World Organisation for Animal Health also suggests that controlling zoonotic pathogens in animals is an effective way of protecting people [2].

Animals have the potential to harbour and spread exotic diseases. The North of Australia is particularly prone to the introduction of exotic diseases due to the vast coastline, remoteness of communities, and the movement of animals and people from neighbouring countries where diseases not yet present in Australia are endemic [3,4]. The implementation and longevity of effective animal health programs in the North of Australia can mitigate overpopulation and improve the health of animals.

This is particularly pertinent in rural and remote Aboriginal communities. People living in rural and remote areas of Australia are more likely to experience greater health concerns and poorer access to health services compared to urban communities [5,6], and this encompasses access to animal health care [7]. Due to this barrier, the poor health of dogs and cats kept as pets can affect human health, particularly where animals and humans live closely together. Large populations of companion animals can lead to increased spread of disease, reduced capacity to prevent disease, and increased risk of physical injury to both animals and humans $[7,8]$. They can also affect the environment and native wildlife populations through predation, disturbances, and disease transmission [9].

A large proportion of communicable diseases in companion animal populations are easily preventable through access to animal medicines and veterinary services, regular treatment, and increased awareness $[10,11]$. Having sick or injured pets can be a cause of stress and worry for people, particularly if there are barriers in accessing animal health care [11,12]. A study of community members in rural and remote Aboriginal communities with limited access to animal health care recognised that parasites (such as mites, fleas, and heartworms) and gastrointestinal diseases (such as salmonella and giardia) are problems encountered in the dog population, as well as noise pollution, dog bites, and destructive behaviour [13]. Dog bites are common in remote communities in North Australia and can be due to large and unmanaged dog populations, causing both physical injury and psychological effects [14,15]. Dogs can also be carriers and reservoirs of zoonotic antimicrobial-resistant bacteria which is a significant public health concern [16].

There is increasing interest in addressing animal health care barriers and public health concerns in low-resourced settings using a One Health approach. One Health is a cross-disciplinary approach that considers the relationships between human, animal, and environmental health [17]. A One Health approach is a holistic approach to animal health and management, aligning with Aboriginal cultural and community contexts and connecting to Aboriginal ways of knowing, doing, and being. An advantage of One Health is the ability to improve wellbeing and health at a community level, rather than just one aspect of society [18]. Studies on dog management in First Nations communities internationally have concluded that strategies for addressing dog population management should involve community participation and consultation, fostering relationships, and support and engagement to be effective $[13,19]$. This is pertinent in Australian Aboriginal communities where dogs have a key role in cultural beliefs, families, and community life $[12,20]$.

A remote community that faces barriers in accessing animal health care is Wadeye in the Northern Territory, Australia. Wadeye has a population of approximately 2280 people, $77 \%$ of whom are Aboriginal [21]. There is very limited access to animal health care and animal medicines with the closest veterinarian an approximately five-hour drive away in the greater Darwin region. A community-driven animal health and management program was implemented in Wadeye to address animal health and population concerns. The aim of this study was to evaluate this program to explore the application of a One Health approach to animal health and management in this setting. 


\section{Materials and Methods}

\subsection{Context}

Due to the barriers in accessing animal health care, the Thamarrurr Development Corporation (TDC) Rangers, along with Animal Management in Rural and Remote Indigenous Communities (AMRRIC), implemented a companion animal health and management program, with support from the West Daly Regional Council. AMRRIC is a not-for-profit organisation that works to deliver veterinary care and animal-related education in rural and remote Aboriginal and Torres Strait Islander communities using a One Health approach.

\subsection{Program Components}

The program consists of five main components including (see Figure 1):

- Co-developed animal health and management program

- The TDC Rangers and AMRRIC started initial discussions in September 2016, followed by an initial veterinary visit and companion animal census in June 2017. The animal health and management program then began in June 2018 and is ongoing.

- $\quad$ Preventative medicines administered to the dog population

- The TDC Rangers administered preventative medicines under veterinary direction, including ivermectin (a broad-spectrum anti-parasitic), to the dog population approximately every three months from February 2018 to June 2019. Afoxolaner (a broad-spectrum anti-parasitic) was administered to dogs that had an observed high burden of parasites. Additional preventative treatments (such as vaccination) were delivered by the visiting veterinary service when required.

- Annual companion animal census

- AMRRIC adapted the census for use in Wadeye. The TDC Rangers, with support from AMRRIC, conducted three annual companion animal censuses from June 2017 to June 2019. The Rangers assist with translating the census questions to community members, as the majority of people do not speak English as a first language.

- $\quad$ AMRRIC visiting veterinary service

- The visiting veterinary service, with assistance from the TDC Rangers, undertook weeklong visits to deliver desexing programs and undertake treatments and surgeries as needed. From June 2018 to June 2019, three veterinary visits occurred in Wadeye with 259 animals receiving treatment, 183 of which were surgically desexed.

- $\quad$ Ongoing training opportunities

- The TDC Rangers undertake training, provided by AMRRIC staff and TDC's Trainer, on recognizing common animal health concerns, preparing and administering preventative medicines, and collecting data. 


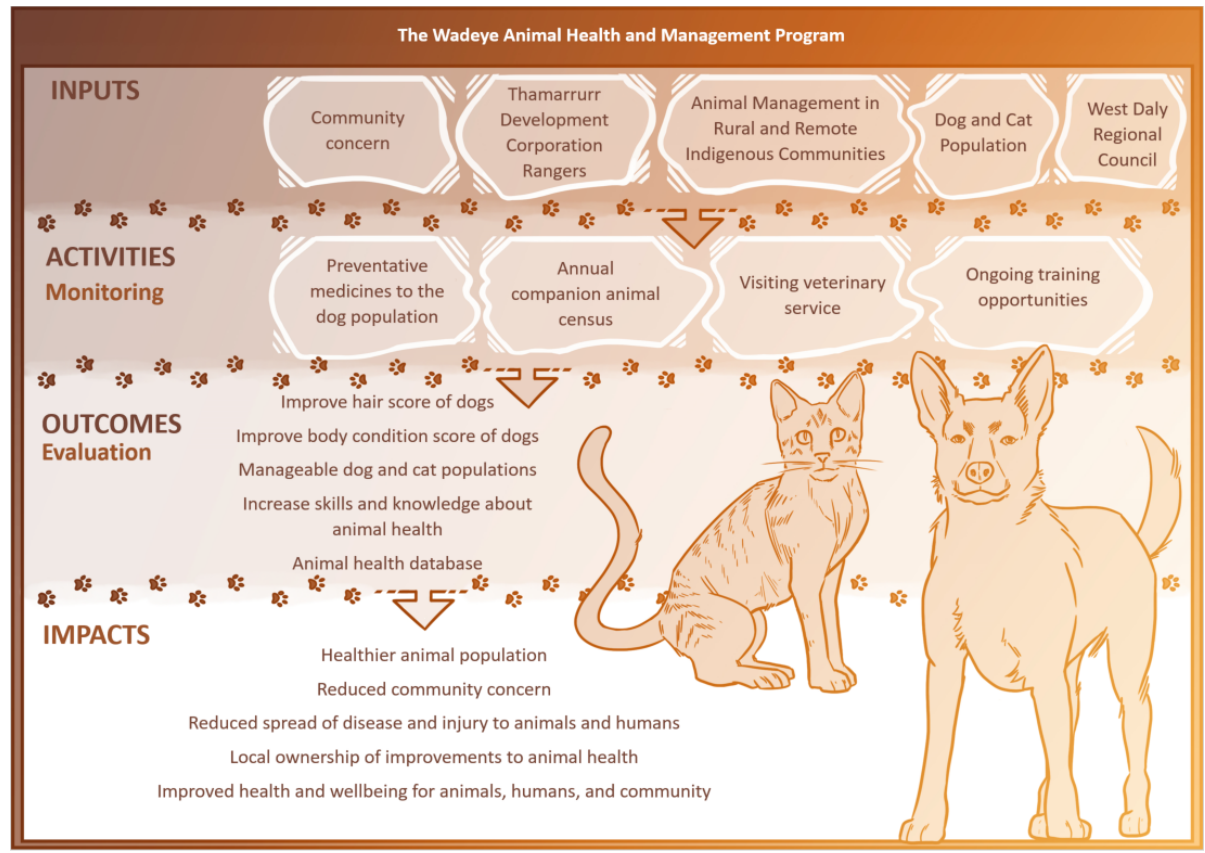

Figure 1. Logic model for the program.

\subsection{Ethics}

Ethics approval was provided by the Human Research Ethics Committee of the Northern Territory Department of Health and Menzies School of Health Research (2018-3176) and the Human Research Ethics Committee at the Australian National University (2018/588).

\subsection{Study Design}

Three data sources were used. A companion animal census was undertaken in June 2017, 2018, and 2019. The Rangers collected the data on a custom-designed AMRRIC app from local community households in Wadeye, with assistance from collaborating organisations. Data were captured at each household by observing the animals and asking the owners about the number of dogs and cats that reside there and their current health and reproductive status. The majority of animals were free-roaming, with mixed-breed medium-sized dogs most commonly seen.

The health outcomes of interest included desexing status (collected as desexed or can breed), body condition score (assessed using the Purina body condition score system and collected as skinny (score 1-3), normal weight (score 4-5), or overweight (score 6-9) [22]), and hair score (collected as good hair, some hair loss, or lots of hair loss). Age of animal was collected by age group including puppy/kitten (still suckling), young (weaning to almost full-grown size), adult (fully-grown size), and old (showing signs of aging or known to be over 5 years of age). Information on the size of the animals and additional health or welfare concerns that required veterinary attention was also captured, however, was not analysed in this study.

Ivermectin was administered at the same time as the census. Veterinary visit data were collected using the AMRRIC app on the number of animals seen and the type of treatments delivered. Dog bite data were collected at the health clinic in Wadeye for any patient that presented with a dog bite and aggregated quarterly from July 2016 to June 2019.

This was a pre-post design analysing three years of companion animal census data to assess animal health pre program implementation (2017) and over the initial 12 months of the program (2018 to 2019). Dog bite data were analysed over four years to assess presentations of dog bite patients to the health clinic, pre program implementation (2016 to 2018), and over the initial 12 months of the program 
(2018 to 2019). Veterinary visit data were also analysed to assess the extent and type of veterinary treatments delivered during the program (2018 to 2019).

An internationally used approach to design and measure companion animal management programs in communities is the International Companion Animal Management Coalition (ICAM) programs and indicators. The indicators focus on animal health, population numbers, and public health to assess the outcomes of the program on the community. Based on the ICAM Coalitions suggested indicators for assessing change, the following indicators and questions were developed [23] (see Table 1).

Table 1. Research questions, evaluation outcomes, indicators, and evaluation questions.

\begin{tabular}{|c|c|c|c|}
\hline Research Questions & $\begin{array}{c}\text { Intended Outcome of } \\
\text { the Program }\end{array}$ & $\begin{array}{l}\text { Indicator Measure of } \\
\text { the Intended Outcome }\end{array}$ & $\begin{array}{c}\text { Specific Evaluation } \\
\text { Question }\end{array}$ \\
\hline \multirow{2}{*}{$\begin{array}{l}\text { What is the state of } \\
\text { animal health in Wadeye } \\
\text { pre program } \\
\text { implementation (2017)? } \\
\text { How does the state of } \\
\text { animal health change } \\
\text { over the period of the } \\
\text { program (2018 to 2019)? }\end{array}$} & $\begin{array}{l}\text { Reduce or stabilise the } \\
\text { animal population }\end{array}$ & $\begin{array}{l}\text { Animals per } 100 \text { people } \\
\text { Age group structure } \\
\text { Breeding females } \\
\text { Animals per household }\end{array}$ & $\begin{array}{c}\text { To what extent were } \\
\text { there changes in the } \\
\text { companion animal } \\
\text { population size and age } \\
\text { distribution? } \\
\text { To what extent were } \\
\text { there changes to } \\
\text { desexing status in the } \\
\text { dog and cat population? }\end{array}$ \\
\hline & Improve animal health & $\begin{array}{c}\text { Body condition score of } \\
\text { dogs } \\
\text { Hair score of dogs }\end{array}$ & $\begin{array}{c}\text { To what extent were } \\
\text { there changes to animal } \\
\text { health outcomes } \\
\text { including dog body } \\
\text { condition and hair score? }\end{array}$ \\
\hline $\begin{array}{c}\text { How many veterinary } \\
\text { treatments are delivered } \\
\text { over the program (2018 } \\
\text { to 2019)? }\end{array}$ & $\begin{array}{l}\text { Improve animal health } \\
\text { care }\end{array}$ & $\begin{array}{c}\text { Preventative and } \\
\text { curative veterinary care } \\
\text { Owner engagement }\end{array}$ & $\begin{array}{l}\text { To what extent were } \\
\text { veterinary care and } \\
\text { animal medicines } \\
\text { delivered? } \\
\text { To what extent were } \\
\text { households engaged in } \\
\text { the program? }\end{array}$ \\
\hline $\begin{array}{l}\text { What is the rate of dog } \\
\text { bite presentations to the } \\
\text { health clinic pre program } \\
\text { implementation } \\
\text { (2016 to 2018)? } \\
\text { How does the rate of dog } \\
\text { bite presentations change } \\
\text { over the program ( } 2018 \\
\text { to 2019)? }\end{array}$ & $\begin{array}{l}\text { Reduce risks to public } \\
\text { health }\end{array}$ & $\begin{array}{l}\text { Total number and rate of } \\
\text { presentations to the } \\
\text { clinic for dog bites }\end{array}$ & $\begin{array}{l}\text { To what extent were } \\
\text { there changes to the rate } \\
\text { of presentations to the } \\
\text { health clinic for a } \\
\text { dog bite? }\end{array}$ \\
\hline
\end{tabular}

\subsection{Variables}

Census data were supplied line-listed by animal and identified by household for each census year. The main outcome variables included desexing status, which was coded as "can breed", "desexed", and "don't know". Body condition score was coded as "underweight", "normal weight", and "overweight". Hair score was coded as "good hair", "some hair loss", and "lots of hair loss". Exposure variables included the year which was coded as "2017", "2018", and "2019". Species was coded as "cat" and "dog". Variables were created to group the number of animals per household, with categories including "1-5", "6-10", "11-15", and "16-24". Age group was coded as "kitten", "adult cat", "puppy", "young dog", "adult dog", and "old dog". Sex was coded as "male", "female", and "don't know". 
Dog bite data were supplied as the quarterly aggregated number of people presenting to the Wadeye health clinic for a dog bite, overall and by sex. Veterinary visit data were supplied as the aggregated number of animals that received each type of treatment at each veterinary visit.

Outcome variables were categorised into binary variables for regression analysis. For all outcomes, responses of "don't know" were coded as "missing" and not included in the analysis. The regression analysis also excluded any animals missing age or sex. Body condition score was coded as "normal weight/overweight" (good body condition) versus "underweight". Hair score was coded as "good hair" (good hair score) versus "any hair loss" (some and lots of hair loss combined). Desexing status was coded as "desexed" versus "not desexed". Year was coded as "2018" and "2019" with 2017 coded as missing, with the exception of hair score which analysed "2017" and "2019", with 2018 coded as missing due to a large amount of missing data.

\subsection{Statistical Analysis}

Statistical analysis was undertaken using Stata 15 and Excel.

Descriptive tables showing counts and percentages were used to summarise animal census data by year for total animal population and each animal health outcome variable. The number of animals per 100 people in Wadeye for three years was calculated using the Australian Bureau of Statistics (ABS) 2016 census population data [21]. The average number of animals per household was calculated using the number of animals divided by the number of households involved in the census each year. Stacked bar charts were created to visualise the distribution of each outcome by year. Veterinary visit data were analysed using descriptive tables broken down by the three veterinary visits and combined overall for a total over 12 months (June 2018-June 2019).

Regression analyses were used to quantify differences in outcomes from pre to post program implementation, comparing data from 2019 (post program implementation) to data from 2018 (pre program implementation). Prevalence ratios (PR) and corresponding 95\% confidence intervals (CIs) were used to compare outcomes (body condition, hair score, and desexing status) in 2019 compared to 2018. In the case of the hair score, data from 2017 were used as the pre-intervention time point (instead of 2018) due to a high level of missing data on the outcome in 2018. All regression models are presented unadjusted and adjusted for age group and sex of the animals because they were potentially confounding variables. Adjusted results are presented in the text. A result was considered significant at a $p$-value of $<0.05$.

Dog bites were presented as quarterly dog bites per 1000 population, by sex of person and overall. ABS 2016 census population data for Wadeye were used as the denominator to calculate crude rates. A time-series analysis was performed on total dog bites comparing July 2016-June 2018 (pre program implementation) to July 2018-June 2019 (the program period).

\section{Results}

\subsection{Animal Population and Health Outcomes}

From 2017 to 2019, the companion animal population decreased from 732 to 633 . Across the years, dogs constituted the majority of pets (81-84\%) in the community, with cats constituting the remaining $16-19 \%$. From 2017 to 2019, there was a decrease in the number of dogs (598 to 532) and cats (134 to 101) owned as pets. There were 32.1 animals per 100 people in 2017 and 27.8 animals per 100 people in 2019 . The average number of animals per household remained relatively stable, with 3.6 in 2017, 3.9 in 2018, and 3.7 in 2019 (see Table 2). 
Table 2. Companion animal population in Wadeye by year.

\begin{tabular}{|c|c|c|c|}
\hline \multicolumn{4}{|c|}{ Companion Animal Population in Wadeye by Year } \\
\hline & 2017 & 2018 & 2019 \\
\hline \multicolumn{4}{|c|}{ Animal population } \\
\hline \multicolumn{4}{|c|}{ Species: \% (n) } \\
\hline Cat & $18(134)$ & 19 (123) & $16(101)$ \\
\hline Dog & $82(598)$ & $81(530)$ & $84(532)$ \\
\hline Total & $100(732)$ & $100(653)$ & $100(633)$ \\
\hline \multicolumn{4}{|c|}{ Animals per 100 people } \\
\hline Cats per 100 people & 5.9 & 5.4 & 4.4 \\
\hline Dogs per 100 people & 26.2 & 23.3 & 23.3 \\
\hline $\begin{array}{l}\text { Total animals per } 100 \\
\text { people }\end{array}$ & 32.1 & 28.6 & 27.8 \\
\hline \multicolumn{4}{|c|}{ Average animals per household } \\
\hline Animals per household & 3.6 & 3.9 & 3.7 \\
\hline \multicolumn{4}{|c|}{ Animal health outcomes } \\
\hline \multicolumn{4}{|c|}{ Dogs desexed: \% } \\
\hline Desexed & 28.6 & 18.5 & 37.0 \\
\hline Not desexed & 57.4 & 54.9 & 46.1 \\
\hline Missing & 14.1 & 26.6 & 16.9 \\
\hline \multicolumn{4}{|c|}{ Cats desexed: \% } \\
\hline Desexed & 14.9 & 22.0 & 30.7 \\
\hline Not desexed & 75.4 & 52.0 & 39.6 \\
\hline Missing & 9.7 & 26.0 & 29.7 \\
\hline \multicolumn{4}{|c|}{ Dogs body condition score: $\%$} \\
\hline Overweight & 1.2 & 0.8 & 3.8 \\
\hline Normal & 62.2 & 48.7 & 76.7 \\
\hline Underweight & 26.3 & 25.9 & 13.9 \\
\hline Missing & 10.4 & 24.7 & 5.6 \\
\hline \multicolumn{4}{|c|}{ Dogs hair score: \% } \\
\hline Normal & 69.4 & 29.1 & 80.3 \\
\hline Any hair loss & 19.2 & 1.5 & 13.5 \\
\hline Missing & 11.4 & 69.4 & 6.2 \\
\hline
\end{tabular}

Across the years, less than half of the dog and cat population was desexed, with the percentage of desexed animals improving over time. The majority of dogs were of normal weight, with very few animals overweight and the underweight population improving over time. The majority of dogs had a good hair score in 2017 and 2019 (2018 data were not analysed due to the amount of missing data) (see Table 2). There were few households with large numbers of animals $(>10)$, with the majority of households having $1-5$ animals (77-82\%) or 6-10 animals (15-23\%) per household. Across the years, the majority of the dogs and cats in Wadeye were adults, with $70.8 \%$ of the dogs and $73.7 \%$ of the cats being adults in 2019. The percentage of old dogs was 3.1\% in 2017 and $9.4 \%$ in 2019.

There was a 150\% increase in the prevalence of desexed dogs from 2018 to 2019 (PR 2.50, 95\%CI 1.70-3.70). Similarly, there was a 125\% increase in the prevalence of desexed cats from 2018 to 2019 (PR 2.25, 95\%CI 1.14-4.47). The prevalence of good body condition in dogs was 77\% higher in 2019 compared to 2018 (PR 1.77, 95\%CI 1.45-2.15). The prevalence of good hair score was $9 \%$ higher in 2019 compared to 2017 (PR 1.09, 95\%CI 1.03-1.16) (see Table 3). 
Table 3. Animal health outcomes in 2019 (post program implementation) compared to 2017/2018 (pre program implementation), unadjusted and adjusted for age group and sex.

\begin{tabular}{|c|c|c|c|c|c|c|c|c|c|c|}
\hline \multicolumn{11}{|c|}{$\begin{array}{l}\text { Animal Health Outcomes in } 2019 \text { (Post Program Implementation) Compared to 2017/2018 (Pre Program } \\
\text { Implementation), Unadjusted and Adjusted for Age Group and Sex }\end{array}$} \\
\hline & $\mathbf{N}$ & $\%$ & $\mathbf{N}$ & $\%$ & $\mathbf{P R}$ & $95 \% \mathrm{CI}$ & $p$ Value & PR & $95 \% \mathrm{CI}$ & $p$ Value \\
\hline \multicolumn{11}{|c|}{ Desexing status of dogs and cats pre and post program implementation (desexed versus not desexed) } \\
\hline Dogs & \multicolumn{2}{|c|}{ Desexed } & \multicolumn{2}{|c|}{ Not desexed } & & \multicolumn{2}{|c|}{ Unadjusted } & \multicolumn{3}{|c|}{ Adjusted for age group and sex } \\
\hline 2018 & 22 & 17.6 & 103 & 82.4 & 1 & & & 1 & & \\
\hline 2019 & 192 & 44.3 & 241 & 55.7 & 2.52 & $1.70-3.74$ & $<0.001$ & 2.50 & $1.70-3.70$ & $<0.001$ \\
\hline Cats & \multicolumn{2}{|c|}{ Desexed } & \multicolumn{2}{|c|}{ Not desexed } & & \multicolumn{2}{|c|}{ Unadjusted } & \multicolumn{3}{|c|}{ Adjusted for age group and sex } \\
\hline 2018 & 7 & 24.1 & 22 & 75.9 & 1 & & & 1 & & \\
\hline 2019 & 31 & 44.3 & 39 & 55.7 & 1.84 & $0.91-3.68$ & 0.088 & 2.25 & $1.14-4.47$ & 0.020 \\
\hline \multicolumn{11}{|c|}{ Dogs body condition pre and post program implementation (normal weight/overweight versus underweight) } \\
\hline Dogs & \multicolumn{2}{|c|}{$\begin{array}{l}\text { Good body } \\
\text { condition }\end{array}$} & \multicolumn{2}{|c|}{ Underweight } & & \multicolumn{2}{|c|}{ Unadjusted } & \multicolumn{3}{|c|}{ Adjusted for age group and sex } \\
\hline 2018 & 53 & 48.2 & 57 & 51.8 & 1 & & & 1 & & \\
\hline 2019 & 419 & 85.0 & 74 & 15.0 & 1.76 & $1.45-2.15$ & $<0.001$ & 1.77 & $1.45-2.15$ & $<0.001$ \\
\hline \multicolumn{11}{|c|}{ Dogs hair score pre and post program implementation (good hair versus any hair loss) } \\
\hline Dogs & \multicolumn{2}{|c|}{ Good hair score } & \multicolumn{2}{|c|}{ Any hair loss } & & \multicolumn{2}{|c|}{ Unadjusted } & \multicolumn{3}{|c|}{ Adjusted for age group and sex } \\
\hline 2017 & 408 & 78.6 & 111 & 21.4 & 1 & & & 1 & & \\
\hline 2019 & 422 & 85.6 & 71 & 14.4 & 1.09 & $1.03-1.15$ & 0.004 & 1.09 & $1.03-1.16$ & 0.003 \\
\hline
\end{tabular}

\subsection{Dog Bites}

The rate of clinical presentations to the health clinic for dog bites per quarter ranged from 1.3 to 7.0 per 1000 population between July 2016 and June 2019. The average quarterly rate pre program implementation was 4.7 , and the average quarterly rate during the program was 4.2 dog bites per 1000 population. There was no difference in dog bites by sex of people presenting to the health clinic. Time-series analysis showed that the rate of dog bite presentations was increasing on average by 0.19 presentations per 1000 population $(9.33+0.19 *$ Time) per quarter before the program was implemented. During program implementation, the rate of dog bites was decreasing on average by 0.20 presentations per 1000 population $(11.20-0.20$ * Time) each quarter. The difference in the slope of the two trends was not significant.

\section{Discussion}

From 2017 to 2019, the companion animal population decreased from 732 to 633. In 2019, there was an average of 3.7 animals per household in Wadeye, almost three times the national average (1.3 animals per household in 2016) [24]. Wadeye had a total of 27.8 animals per 100 people, with more dogs (23.3 dogs per 100 people) compared to the Australian average ( 20.0 dogs per 100 people). It is important to note that on average households have a higher number of people in Wadeye (6.1 people per household) compared to the Australian average (3.2 people per household); therefore, we can expect more animals per household [21]. There were substantially fewer cats in Wadeye (4.4 cats per 100 people) compared to the Australian average (16.0 cats per 100 people) [24]. Both animal and human population numbers are a snapshot and do not take into account changes to the populations over time. Wadeye is a large remote community; however, as this program focuses on maintaining animal population control and improving animal health, this program may also be suitable for communities with smaller animal populations.

The results show that after program implementation all animal health outcomes improved significantly. The prevalence of desexed dogs and cats more than doubled in 2019 compared to 2018. There was a 77\% increase in the prevalence of good body condition in dogs in 2019 compared to 2018 and a 9\% increase in the prevalence of good hair score in 2019 compared to 2017. There was also a decrease in the overall animal population size, an aging dog population, and fewer households with large numbers 
of animals. Due to the non-randomised, pragmatic nature of the evaluation, these improvements cannot be solely attributed to the program. However, the observed improvements were consistent with the hypothesised outcomes of the program, and the improvements occurred following program implementation. We therefore expect that at least some of the observed improvements can be attributed to the program itself.

Sustained animal health and management programs are important components in remote communities to keep animal populations healthy and manageable. Desexing animals can lead to a more manageable animal population and fewer animal-associated injuries [25]. Reaching a stable population is supported by desexing to counteract the rate of reproductive success in breeding females [10]. Dogs can be underweight and have hair loss due to high burdens of parasites and may also be underweight due to the effects of continual breeding, among other causes. Additionally, keeping animals healthy and reducing breeding can lead to an aging and manageable animal population with fewer animals per household. This may reduce the risk of communicable diseases transmitting to other animals and people [10]. Community-led approaches to addressing animal health concerns can be a feasible and sustainable option for controlling zoonoses and could be assessed by collecting human health data on zoonotic diseases affecting people in communities [18]. Increasing community awareness and local skills and knowledge can also assist in building effective animal management programs, with community ownership of the program beneficial [26].

There was no observed significant difference in dog bites pre to post program, overall and by sex; however, the dog bite findings were consistent with a decrease in the rate of dog bites in the community over the period of program implementation, compared to pre program implementation. The average quarterly rate pre program was $4.7 \mathrm{dog}$ bite presentations per 1000 population, and the average quarterly rate during the program was $4.2 \mathrm{dog}$ bites per 1000 population. The dog bite data relied on a dog bite injury being of sufficient severity to require medical attention; therefore, this analysis does not capture injuries that were not severe enough to require treatment.

To see programs such as this be sustainable and continue in communities, ongoing access to resources is needed. Building monitoring and evaluation capacity into program designs can produce evidence of the impact of the program, assess if the program is meeting community needs, and lead to increased support and funding $[27,28]$. Enhanced partnerships and collaboration between the animal, human, and environmental health sectors will assist in delivering a One Health approach [18]. Similarly, using evidence to influence the policy environment may lead to government-level support for One Health programs. The Northern Territory does not have companion animal management legislation, however, discussions are in place to enact this [29]. This means that currently there is no territory-wide legislation regarding companion animal management, and therefore, animal management is not consistently resourced or delivered between local government regions.

The strengths of this study include the inclusion of an annual census of the animal population before the program was developed, at the start of the program, and 12 months later, allowing a quantitative evaluation of the program. The community-driven component of this program was vital, with the involvement of community members likely to lead to a greater chance of the continuation of the program. The community-driven arrangement of the program allowed the Rangers to build on their skills and knowledge about animal health and management, leading to a higher likelihood of sustainability of the program. Additionally, this program had cooperation and support from multiple sectors including the local council, federal government, a not-for-profit animal health organisation, a Ranger group, and research scientists working in partnership and fostering a One Health approach.

The limitations of this study include the lack of completeness of the census data, as there is a substantial amount of missing data (including responses of "don't know") over the three years. In 2018, this was mainly due to technical issues. The prevalence of missing data was lower in 2019 than in previous years for most outcomes. This may be due to holding detailed refresher training with the Rangers, and the increasing experience with using the census app by delivering it annually. The analysis of dog bites had limitations as the data were supplied aggregated and the April-June 2018 
quarter could not be separated into pre and post program implementation. There were also not enough time points to run an interrupted time-series analysis on the data. Collecting data on this outcome at additional time points would increase the power in conducting the interrupted time series analysis. This analysis could also be strengthened by collecting information about how the dog bites occurred, as dog bites may be in response to human behaviour and not related to the overpopulation of animals.

The inability to link animal health and human health from the same household limits the relationships we can draw between improvements in health outcomes [30]. Further consideration could be given on how to implement an enhanced One Health model in this setting to improve the health of all aspects of the community. This could be achieved through improving partnerships and communication between animal, human, and environmental health sectors and programs within communities [31]. Multi-disciplinary approaches to designing, implementing, and evaluating programs and the ability to collect integrated household-level data on animal and human health simultaneously could assist with this [18]. Future studies could consider additional components and indicators to assess community engagement with the program and assess if the program is meeting community needs [32].

\section{Conclusions}

This study showed the positive effects on animal health observed over the initial 12 months of a community-driven and One Health approach to animal health and management in a remote community. From June 2018 to June 2019, three veterinary visits were delivered with 259 animals receiving treatment. All animal health outcomes significantly improved and there was a decrease in the overall animal population, an aging dog population, and fewer households with large numbers of animals.

A One Health approach can be appropriate in this setting as it considers the relationships between animals, humans, and the environment, with improvement in animal health having the potential to improve human health and overall community wellbeing. Many programs such as this may not be supported long-term and rely on obtaining support and external funding to continue. The leadership of the community in implementing this program is vital to its sustainability, and through increasing skills and knowledge around animal health and management, this program has a greater chance of continuing. Future programs could consider incorporating a formal evaluation component to be able to produce and publish evidence of the impact of the program and assist in gaining continuing support.

Author Contributions: Conceptualization, T.R., R.L., B.C., and K.A.T.; Formal analysis, T.R. and J.T.; Methodology, T.R., R.L., J.T., B.C., and K.A.T.; Project administration, T.R., R.L., B.C., and K.A.T.; Software, B.C.; Supervision, R.L. and K.A.T.; Writing—original draft, T.R.; Writing—review and editing, T.R., R.L., J.T., B.C., and K.A.T. All authors have read and agreed to the published version of the manuscript.

Funding: Tamara Riley was supported by an Australian National University Masters Scholarship.

Acknowledgments: We would like to acknowledge the pet owners in Wadeye who took part in the program, as well as the Thamarrurr Development Corporation (TDC) Rangers, the West Daly Regional Council, and Animal Management in Rural and Remote Indigenous Communities (AMRRIC). We would also like to acknowledge Erin Walsh from the Research School of Population Health at the Australian National University who provided the design for the logic model. AMRRIC would like to acknowledge the National Indigenous Australians Agency which provides support for their operations.

Conflicts of Interest: The authors declare no conflict of interest. The funders had no role in the design of the study; in the collection, analyses, or interpretation of data; in the writing of the manuscript, or in the decision to publish the results.

\section{References}

1. World Health Organization. The Control of Neglected Zoonotic Diseases: A Route to Poverty Alleviation: Report of a Joint WHO; World Health Organization: Geneva, Switzerland, 2006; p. 65, Report No.: 9241594306.

2. Corning, S. World Organisation for Animal Health: Strengthening Veterinary Services for effective One Health collaboration. Rev. Sci. Tech. (Int. Off. Epizoot.) 2014, 33, 639-650. [CrossRef] [PubMed] 
3. Australian Government Department of Agriculture and Water Resources. Northern Australia Quarantine Strategy Canberra ACT: Australian Government Department of Agriculture and Water Resources. 2017. Available online: http://www.agriculture.gov.au/biosecurity/australia/naqs (accessed on 26 March 2020).

4. Degeling, C.; Lea, T.; Brookes, V.J.; Ward, M. Rabies response, One Health and more-than-human considerations in Indigenous communities in northern Australia. Soc. Sci. Med. 2018, 212, 60-67. [CrossRef] [PubMed]

5. Australian Institute of Health and Welfare. Australia's Welfare 2017: In Brief; Australian Institute of Health and Welfare: Canberra, Australia, 2017.

6. Quinn, E.; Massey, P.; Speare, R. Communicable diseases in rural and remote Australia: The need for improved understanding and action. Rural. Remote Heal. 2015, 15, 1-19.

7. Caroll, T.; Khan, A.; Bell, G.; Standen, J. Evaluation of a Dog Health Program in an Aboriginal Community in Northern NSW. Aborig. Isl. Health Worker J. 2011, 35, 28-29.

8. Schurer, J.M.; Phipps, K.; Okemow, C.; Beatch, H.; Jenkins, E. Stabilizing Dog Populations and Improving Animal and Public Health Through a Participatory Approach in Indigenous Communities. Zoonoses Public Health 2014, 62, 445-455. [CrossRef]

9. Kennedy, B.; Brown, W.Y.; Vernes, K.; Körtner, G.; Butler, J.R. Dog and Cat Interactions in a Remote Aboriginal Community. Animals 2018, 8, 65. [CrossRef] [PubMed]

10. International Companion Animal Management Coalition. Humane Dog Population Management Guidance; International Companion Animal Management Coalition: London, UK, 2019; p. 104.

11. Constable, S.; Brown, G.; Dixon, R.M.; Dixon, R.J. Healing the Hand that Feeds You: Exploring Solutions for Dog and Community Health and Welfare in Australian Indigenous Cultures. Int. J. Interdiscip. Soc. Sci. Annu. Rev. 2008, 3, 219-230. [CrossRef]

12. Ma, G.C.; Ford, J.; Lucas, L.; Norris, J.M.; Spencer, J.; Withers, A.-M.; Ward, M.P. “They Reckon They're Man's Best Friend and I Believe That." Understanding Relationships with Dogs in Australian Aboriginal Communities to Inform Effective Dog Population Management. Animals 2020, 10, 810. [CrossRef]

13. Constable, S.E.; Dixon, R.M.; Toribio, J.-A. Approaches to dog health education programs in Australian rural and remote Indigenous communities: Four case studies. Heal. Promot. Int. 2012, 28, 322-332. [CrossRef]

14. Dhillon, J.; Favel, D.; Delorme, D.; Ratt, A.; Epp, T. Finding pathways for bite prevention and decreasing dog populations: The process of animal control for indigenous communities in Canada. J. Indig. Wellbeing 2016, 2, 82-92.

15. Hudson, E.G.; Brookes, V.J.; Ward, M.P. Assessing the Risk of a Canine Rabies Incursion in Northern Australia. Front. Veter. Sci. 2017, 4. [CrossRef] [PubMed]

16. Rusdi, B.; Laird, T.; Abraham, R.; Ash, A.; Robertson, I.D.; Mukerji, S.; Coombs, G.W.; Abraham, S.; O'Dea, M.A. Carriage of critically important antimicrobial resistant bacteria and zoonotic parasites amongst camp dogs in remote Western Australian indigenous communities. Sci. Rep. 2018, 8, 8725. [CrossRef] [PubMed]

17. One Health Commission. What is One Health? Apex NC: One Health Commission. 2018. Available online: https://www.onehealthcommission.org/en/why_one_health/what_is_one_health/ (accessed on 26 March 2020).

18. Molyneux, D.H.; Hallaj, Z.; Keusch, G.T.; McManus, D.P.; Ngowi, H.; Cleaveland, S.; Ramos-Jimenez, P.; Gotuzzo, E.; Kar, K.K.; Sanchez, A.; et al. Zoonoses and marginalised infectious diseases of poverty: Where do we stand? Parasites Vectors 2011, 4, 106. [CrossRef] [PubMed]

19. Dhillon, J.M. Dog Population Management and Dog Bite Prevention in Rural and Remote Northern Saskatchewan Aboriginal Communities. Ph.D. Thesis, University of Saskatchewan, Saskatoon, SK, Canada, 2017.

20. Constable, S.; Dixon, R.; Dixon, R. For the Love of Dog: The Human-Dog Bond in Rural and Remote Australian Indigenous Communities. Anthrozoös 2010, 23, 337-349. [CrossRef]

21. Australian Bureau of Statistics. 2016 Census QuickStats: Wadeye, Canberra ACT: Australian Bureau of Statistics. 2016. Available online: http://quickstats.censusdata.abs.gov.au/census_services/getproduct/census/ 2016/quickstat/SSC70275 (accessed on 26 March 2020).

22. Purina. Body Condition System USA: University of Missouri. 2015. Available online: http://vhc.missouri. edu/wp-content/uploads/2015/07/BodyConditionScoreCharts.pdf (accessed on 17 August 2020). 
23. International Companion Animal Management Coalition. Are We Making a Difference? A Guide to Monitoring and Evaluating Dog Population Management Interventions 2015; International Companion Animal Management Coalition: London, UK, 2015; p. 132.

24. Animal Medicines Australia. Pet Ownership in Australia 2016; Newgate Research: Canberra, Australia, 2016.

25. D'Onise, K.; Hazel, S.; Caraguel, C.G. Mandatory desexing of dogs: One step in the right direction to reduce the risk of dog bite? A systematic review. Inj. Prev. 2017, 23, 212-218. [CrossRef]

26. Lembo, T.; Attlan, M.; Bourhy, H.; Cleaveland, S.; Costa, P.; De Balogh, K.; Dodet, B.; Fooks, A.R.; Hiby, E.; Leanes, F.; et al. Renewed Global Partnerships and Redesigned Roadmaps for Rabies Prevention and Control. Veter. Med. Int. 2011, 2011, 1-18. [CrossRef]

27. Baker, T.; Kutz, S.; Toews, L.C.; Edwards, N.; Rock, M.J. Are we adequately evaluating subsidized veterinary services? A scoping review. Prev. Veter. Med. 2018, 157, 59-69. [CrossRef]

28. Baker, T.; Rock, M.J.; Brook, R.; Van Der Meer, F.; Kutz, S. Indigenous community perspectives on dogs in Northern Canada after 10 years of veterinary services indicates improved animal and human welfare. Prev. Veter. Med. 2020, 181, 105061. [CrossRef]

29. Australian Veterinary Association. Uniform Companion Animal Legislation in the Northern Territory; Discussion paper consultation; Australian Veterinary Association: Sydney, NSW, Australia, 2020; pp. 1-10.

30. Smout, F.A.; Schrieber, L.; Speare, R.; Skerratt, L.F. More bark than bite: Comparative studies are needed to determine the importance of canine zoonoses in Aboriginal communities. A critical review of published research. Zoonoses Public Health 2017, 64, 495-504. [CrossRef]

31. Johnson, I.; Hansen, A.; Bi, P. The challenges of implementing an integrated One Health surveillance system in Australia. Zoonoses Public Health 2017, 65, e229-e236. [CrossRef]

32. Ma, G.C.; Withers, A.-M.; Spencer, J.; Norris, J.M.; Ward, M.P. Evaluation of a Dog Population Management Intervention: Measuring Indicators of Impact. Animals 2020, 10, 1061. [CrossRef] [PubMed]

(C) 2020 by the authors. Licensee MDPI, Basel, Switzerland. This article is an open access article distributed under the terms and conditions of the Creative Commons Attribution (CC BY) license (http://creativecommons.org/licenses/by/4.0/). 